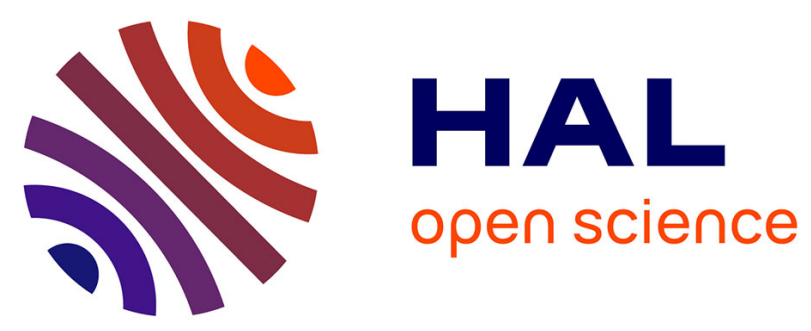

\title{
Graphical method for the phase noise optimization applied to a 6-GHz fully integrated NMOS differential LC VCO
}

Dorra Mellouli, David Cordeau, Jean-Marie Paillot, Hasséne Mnif, Mourad Loulou

\section{To cite this version:}

Dorra Mellouli, David Cordeau, Jean-Marie Paillot, Hasséne Mnif, Mourad Loulou. Graphical method for the phase noise optimization applied to a $6-\mathrm{GHz}$ fully integrated NMOS differential LC VCO. IEEE 9th International New Circuits and Systems Conference, Jun 2011, Bordeaux, France. pp.85-88. hal00683381

\section{HAL Id: hal-00683381 https://hal.science/hal-00683381}

Submitted on 28 Mar 2012

HAL is a multi-disciplinary open access archive for the deposit and dissemination of scientific research documents, whether they are published or not. The documents may come from teaching and research institutions in France or abroad, or from public or private research centers.
L'archive ouverte pluridisciplinaire HAL, est destinée au dépôt et à la diffusion de documents scientifiques de niveau recherche, publiés ou non, émanant des établissements d'enseignement et de recherche français ou étrangers, des laboratoires publics ou privés. 


\section{Graphical method for the Phase noise Optimization applied to a $6-\mathrm{GHz}$ fully integrated NMOS differential LC VCO}

Dorra Mellouli, David Cordeau, Jean -Marie Paillot LAII

University of Poitiers

Angoulême, France

dorra.mellouli@ieee.org; david.cordeau@univ-poitiers.fr ; jean.marie.paillot@univ-poitiers.fr

\author{
Hassene Mnif , Mourad Loulou \\ Research Unit on Electronics and Information Technologies \\ ENIS, University of Sfax \\ Sfax, Tunisia
}

Hassene.mnif@ieee.org; mourad.loulou@ieee.org

\begin{abstract}
This paper describes the design and the optimization in terms of phase noise of a fully integrated NMOS Voltage Controlled Oscillator (VCO) using a $0.25 \mu \mathrm{m}$ BICMOS SiGe process. A three-dimensional phase noise analysis diagram and a graphical optimization approach is presented to optimize the phase noise of the VCO while satisfying design constraints such as tank amplitude, power dissipation, tuning range and start up conditions. At $2.5 \mathrm{~V}$ power supply voltage, the optimized VCO features a simulated phase noise of $-118 \mathrm{dBc} / \mathrm{Hz}$ at $1 \mathrm{MHz}$ frequency offset from a $6.12 \mathrm{GHz}$ carrier. The VCO is tuned from $6.1 \mathrm{GHz}$ to $7.9 \mathrm{GHz}$ with a tuning voltage varying from 0 to $2.5 \mathrm{~V}$, and a power dissipation of only $7.4 \mathrm{~mW}$.
\end{abstract}

Keywords: phase noise, Optimization, graphical method, VCO, NMOS technology.

\section{INTRODUCTION}

Voltage controlled oscillators are essential building blocks of modern RF transceivers architectures. The VCO performances in terms of tuning range, power dissipation and phase noise determine most of the basic performances of a complete transceiver.

Due to the evolution of wireless communication systems, the design of integrated oscillators implies many challenges to circuit designers as it involves multiple variables. To overcome these challenges and optimize the phase noise of the oscillator, an accurate graphical optimization method is presented in [1] by Hajimiri \& al. The process of this optimization is performed through the minimization of phase noise while satisfying all different design constraints such as startup conditions, tank amplitude and tuning range. Nevertheless, in [1], the bias current of the VCO, which is an important parameter for the phase noise optimization, is chosen arbitrary to the maximum current allowed by the specifications. This choice does not constitute an optimal optimization strategy. Indeed, let us remind that a simplified and widely used phase noise model separates the amplitude behavior versus the bias current into two operation modes named voltage and current-limited regimes [2]. Thus the phase noise decreases in the first regime until it reaches the stable transition point located between the two regimes. So, the desired bias current point for the optimum phase noise and power consumption performances is located at the intersection of these two regimes.

Due to this considerations, the aim of this work is first, to determine the optimum bias current of the VCO using a three dimensional phase noise representation using a parametric analysis and second, starting from this optimal current, to use the graphical optimization method proposed in [1] and adapted to our $6 \mathrm{GHz}$ NMOS only LC VCO architecture.

This paper is organized as follow. In section II, the cross coupled LC-VCO architecture chosen as application example for the proposed method is described. The graphical optimization method is also presented in detail for the chosen LC VCO architecture. Section III presents the simulation results of the optimized VCO in order to show the accuracy of the presented method. Finally, we give some concluding remarks in section IV.

\section{VCO TOPOLOGY AND OPTIMIZATION APPROACH}

\section{A. VCO topology}

Figure 1 shows the simplified VCO schematic used and based on the well-known cross-coupled NMOS differential topology. The LC tank is made of a symmetric center-tapped inductor and a differentially tuned varactor. The cross connected NMOS differential pair provides the negative resistance to compensate for the tank losses. The tail current source is a simple NMOS current mirror. In these conditions, the width and the length of the NMOS tail transistor must be increased to reduce the flicker noise which lowers significantly the close-in phase noise of the VCO [3]. A tail 
capacitor $\mathrm{C}_{\mathrm{T}}$ is used to attenuate both the high-frequency noise component of the tail current and the voltage variations on the tail node. This latter effect results in more symmetric waveforms and smaller harmonic distortion in LC-VCO outputs [4], [5].

\section{B. Optimization approach}

For this LC VCO architecture, the adopted optimization methodology which is based on the following steps is detailed:

- $\quad$ Specifications definition ;

- $\quad$ VCO model determination ;

- Optimum Bias conditions determination;

- $\quad$ Phase noise graphical optimization ;

- Phase noise estimation using the optimum parameter found in the previous step.

In the following sub sections, the process of modelization and optimization of the LC-VCO topology is analyzed step by step.

\section{1) VCO model determination}

The equivalent circuit model of the oscillator is shown in Figure 2, where the broken line in the middle represents either the common mode or ground.

The frequently appearing parameters in this model are the tank loss $g_{\text {tank}}$, effective negative conductance $g_{\text {active, }}$ tank inductance $L_{\text {tank }}$ and tank capacitance $C_{\text {tank }}$ given by:

$$
\begin{gathered}
2 g_{\text {tank }}=g_{d}+g_{v}+g_{L} \\
2 g_{\text {active }}=g_{m} \\
L_{\text {tank }}=2 L \\
2 C_{\text {tank }}=4 C_{g d}+C_{d b}+C_{g s}+C_{L}+C_{V}
\end{gathered}
$$

\section{a) Inductor model}

As explained in section II-A, the inductor used is a symmetric center-tapped inductor. The global inductance value is about $1.2 \mathrm{nH}$ and the differential quality factor is equal to 19 at $6 \mathrm{GHz}$. Let us note here that we consider that the inductor has been designed in order to obtain a maximum $\mathrm{Q}$ factor at $6 \mathrm{GHz}$. Using the model in [1], the effective parallel equivalent conductance of the inductor, $g_{\mathrm{L}}$, is given by:

$$
g_{L}=\frac{1}{R_{p}}+\frac{R_{s}}{(\omega L)^{2}}
$$

where $R_{\mathrm{p}}$ and $R_{\mathrm{s}}$ represents the parasitical elements of the inductance.

\section{b) Varactor model}

The varactor used is based on NMOS transistors in inversion mode. We modelize the varactor as an ideal capacitance in series with a resistor $R_{\mathrm{v}}$. The varactor quality factor is equal to 200 at $6 \mathrm{GHz}$, and the effective parallel equivalent varactor conductance, $g_{\mathrm{v}}$, is then given by:
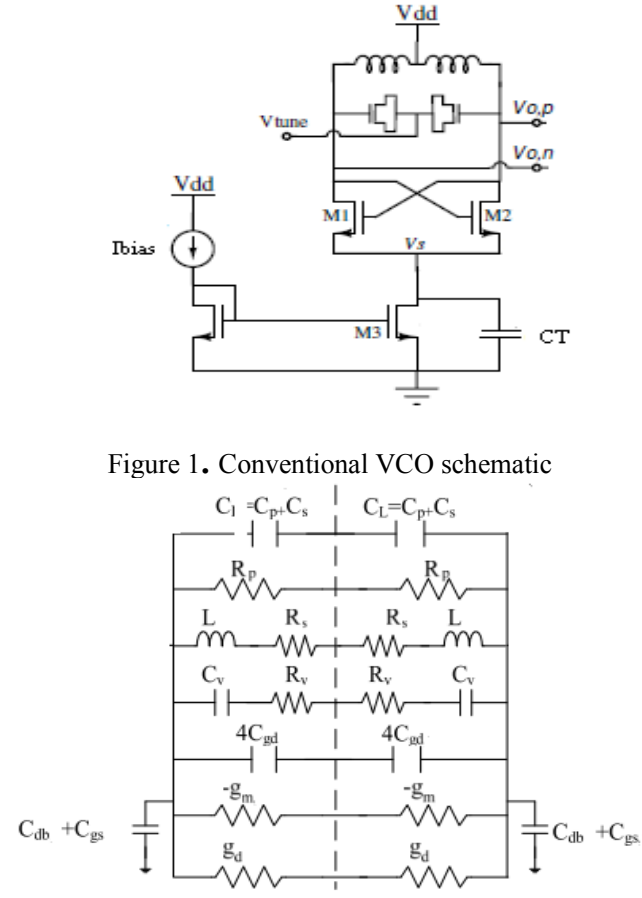

Figure 2. Equivalent oscillator model

$$
g_{V}=\frac{1}{R_{v}}=\frac{C_{v} \omega}{Q_{v}}
$$

Where $R_{\mathrm{v}}$ is the MOS varactor parasitic serie resistance and $Q_{\mathrm{v}}$ represent the quality factor of the varactor.

\section{c) Transistor model}

The very useful NMOS transistor analytical model described in [6] is used for the graphical optimization and visualization of design constraints.

\section{2) Optimum Bias conditions determination}

Let us remind that the aim of this part is to determine the optimum bias current of the VCO for a minimum phase noise. To do so, a program developed in Maple in which we exploit the following expression describing the phase noise model (pn) of the VCO is used [7].

$$
\operatorname{Pn}\left(f_{\text {offset }}\right)=\left[\frac{1}{16 \pi^{2} f_{\text {offset }}^{2}} \cdot \frac{L^{2}\left(2 \pi f_{0}\right) 2}{V_{\mathrm{tank}}^{2}}\right]\left[2 k T\left(g_{L}+g_{v}+\gamma g_{d}\right]\right.
$$

Where $\mathrm{k}$ is the Boltzmann constant, $\mathrm{T}$ is the temperature, $V_{\text {tank }}$ is the oscillation amplitude, $\mathrm{f}_{0}$ is the oscillation frequency, $f_{\text {offset }}$ is the offset frequency from the carrier, $\gamma$ is equal to $5 / 2$ and $g_{d}$ is the output conductance.

So, for each value of $I_{\text {bias }}$ the tank voltage and the phase noise are calculated using equation 8 . Figure 3 shows a threedimensional representation of the LC-VCO phase noise. In this figure, the $(\mathrm{x}-\mathrm{y})$ plane describes the bias condition of the $\mathrm{VCO}$ and the z-axis corresponds to phase noise prediction. Thus, an initial optimal bias condition for which the phase noise is estimated to be at the minimum is selected. The 
coordinate of this minimum for this $6-\mathrm{GHz} \mathrm{VCO}$ is given by: $I_{\text {bias }}=3.4 \mathrm{~mA}$ and $P \mathrm{n}(1 \mathrm{MHz})=-116.71 \mathrm{dBc} / \mathrm{Hz}$.

\section{3) Phase noise graphical optimization}

Using the previous model for the chosen LC VCO, the process of optimization consists in the representation of the design constraints in the variable plane; therefore let us, first of all, define the design variables.

\section{a) Design variables}

There are many initial design variables associated with the specified VCO: the geometric parameters of the on-chip spiral inductors, the MOS transistors dimensions ( $W_{\mathrm{n}}$ and $\left.L_{\mathrm{n}}\right)$ and the maximum and minimum values of the varactors $\left(C_{\mathrm{v}, \max }\right.$ and $\left.C_{\mathrm{v}, \min }\right)$. The number of these design variables can be reduced as explained in the following: First, the geometric parameters of the inductors are fixed in order to obtain a high inductor quality factor as mentioned previously. Second, the channel length $\mathrm{Ln}$ is set to the minimum allowed by the process technology for maximum transition frequency $\left(\mathrm{F}_{\mathrm{T}}\right)$ and transconductance $g_{\mathrm{m}}$. Third, the ratio $C_{\mathrm{v}, \max } / C_{\mathrm{v}, \min }$ is maximum. Therefore, the varactor introduces only one design $\operatorname{variable}\left(C_{\mathrm{v}, \max }\right)$.

Finally, we reduce the number to only two design variables, the transistors width $\mathrm{Wn}$ and the maximal varactor capacitance $C_{\mathrm{v}, \max }$ which will be referred to $C$ in the following. Consequently, the design constraints will be represented in the $(W \mathrm{n}, C)$ plane.

\section{a) Design constraints}

The main goal of the optimization is to minimize the phase noise of the VCO while satisfying all design constraints such as tank amplitude, startup condition, power dissipation and tuning range.

In these conditions, and in order to ensure a large enough voltage swing, the tank amplitude is required to be larger than $V_{\text {tank,min }}$ so that:

$$
V_{\text {tank }}=\frac{I_{\text {bias }}}{g_{\text {tank, } \max }} \geq V_{\text {tank, } \text { min }}
$$

Where $V_{\text {tank,min }}$ is chosen to be equal to $1 \mathrm{~V}$ and $g_{\text {tank,max }}$ is the maximum tank conductance.

Moreover, the startup condition is fixed by:

$$
g_{\text {active }} \geq \sigma_{\min } g_{\text {tank, } \max }
$$

Where $\sigma_{\min }=3$ is the small-signal loop gain, $g_{\text {active }}$ and $g_{\text {tank,max }}$ are the active and the tank conductance respectively.

Finally, the oscillation tuning range is limited by two values depending on the center frequency $\omega_{0}$, so that:

$$
\begin{aligned}
& L_{\text {tank }} C_{\text {tank, min }} \leq \frac{1}{\omega_{\text {max }} 2} \\
& L_{\text {tank }} C_{\text {tank, max }} \geq \frac{1}{\omega_{\text {min }} 2}
\end{aligned}
$$

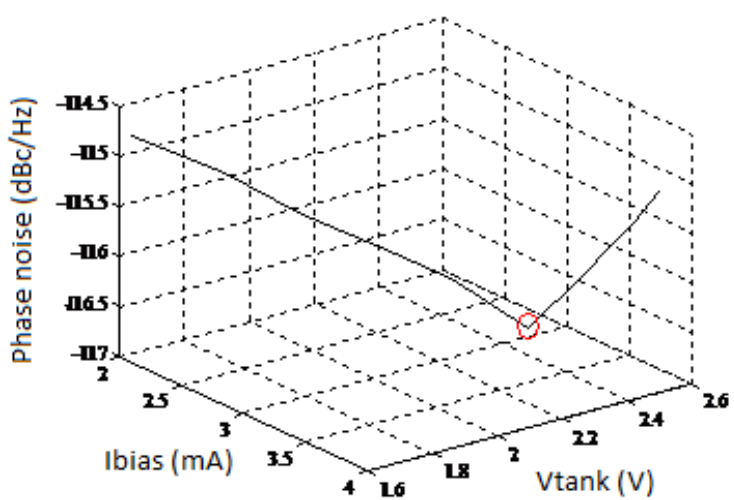

Figure 3. Calculated phase noise versus $V_{\text {tank }}$ and $I_{\text {bias }}$

The design constraints given by (8) to (11) are expressed and formulated as functions of $W_{\mathrm{n}}$ and $C$ variables, and a new program was developed in Maple which allows to calculate, for each value of the transistor width, the varactor capacitance $C$ so that the design constraints are fulfilled. The associated curves are shown in figure 4 , using the initial $I_{\text {bias }}$ condition already determined.

The line representing the limit of the tank amplitude is obtained using (8), the region below this line corresponds to $\mathrm{V}_{\text {tank }}$ greater than $1 \mathrm{~V}$. The $\operatorname{tr}_{1}$ and $\operatorname{tr}_{2}$ lines define the maximum and minimum frequency of the tuning range, and are obtained respectively from (10) and (11). In this case, a tuning range of $25 \%$ with a center frequency of $6 \mathrm{GHz}$ is obtained if a design point (a couple $C, W_{\mathrm{n}}$ ) lies between the tr 1 line and the $\operatorname{tr}_{2}$ line. The startup line is obtained from (9).Thus, to ensure proper startup of the VCO, the point must be located on the right-hand side of the startup line for $\sigma \mathrm{min}=3$. Finally the regime divider line presents the limit of the voltage-limited regime and the current-limited regime.

The region with shadow in figure 4(a) satisfies all the design constraints and represents a set of feasible design points. The optimum point is defined by the intersection of the startup line and $\operatorname{tr}_{2}$ line since this point corresponds to the low parasitic capacitances values. However we can notice that the optimum point is located in the voltage limited regime (below the regime divider). Therefore, the design suffers from waste of power. As a consequence, the bias current must be reduced until the optimum is located on the regime divider line. In this case, figure 4(b) shows the optimum design with $I_{\text {bias }}=2.95$ $\mathrm{mA}$ for which no further action is necessary.

Consequently, the obtained optimum point is defined by: $W \mathrm{n}=18 \mu \mathrm{m} ; C=C_{\mathrm{v}, \max }=0.55 \mathrm{pF}$ and $I_{\text {bias }}=2.95 \mathrm{~mA}$.

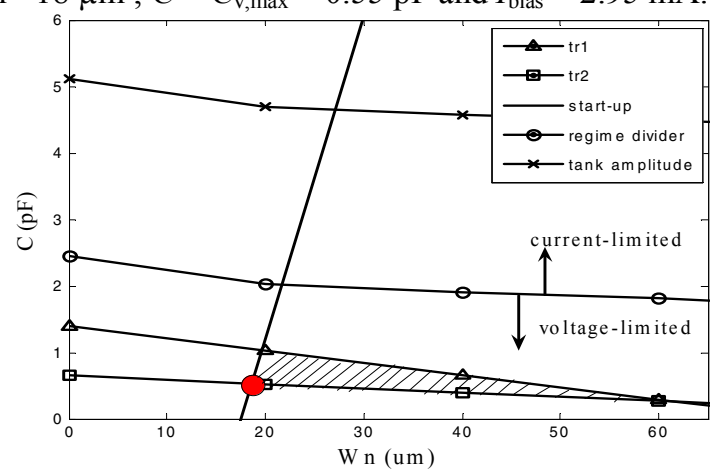

(a) 


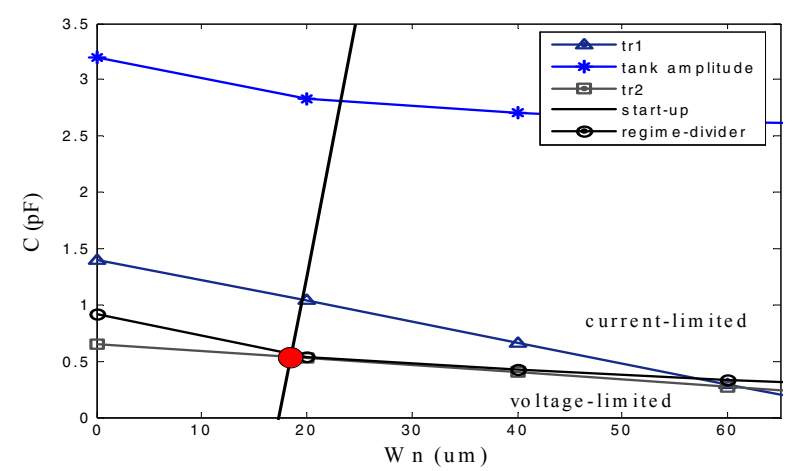

(b)

Figure 4. Design constraints for: (a) $I_{\text {bias }}=3.4 \mathrm{~mA}$; (b ) $I_{\text {bias }}=2.95 \mathrm{~mA}$

\section{SIMULATION RESULTS}

In this section, simulations using spectre RF Software is performed on the VCO designed using the presented optimization process.

At the beginning, one must verify that the $I_{\text {bias }}$ point found through the optimization method is effectively the optimum current for minimum phase noise. To do so, the phase noise at $1 \mathrm{MHz}$ frequency offset versus the bias current is plotted. The curve in figure 5 shows that the phase noise decreases in the first regime and it reaches the stable transition point located between the voltage and current limited regimes. This transition point is defined by a current whose value is located between $2.9 \mathrm{~mA}$ and $3.1 \mathrm{~mA}$.

Furthermore, as shown in figure 6 , the VCO can be tuned from $6.1 \mathrm{GHz}$ to $7.9 \mathrm{GHz}$, and shows a phase noise of -118 $\mathrm{dBc} / \mathrm{Hz}$ at $1 \mathrm{MHz}$ frequency offset from a $6.12 \mathrm{GHz}$ carrier, and a current consumption of $2.95 \mathrm{~mA}$ from a $2.5 \mathrm{~V}$ power supply.

In order to show the accuracy of the presented graphical optimization method, table I presents a comparison between theoretical (presented method) and simulation (Spectre RF software) results. Let us note that, the phase noise value is calculated using (7) after optimization. As we can see, a good agreement can be found between theoretical and simulated results.

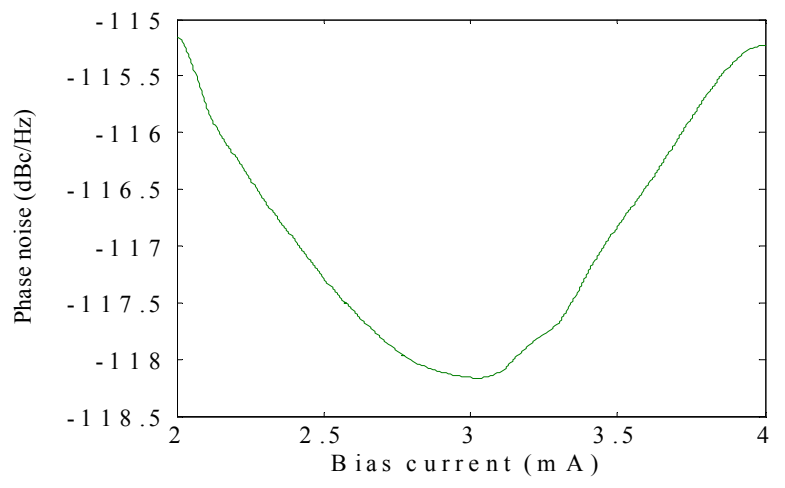

Figure 5. Phase noise versus the bias current.

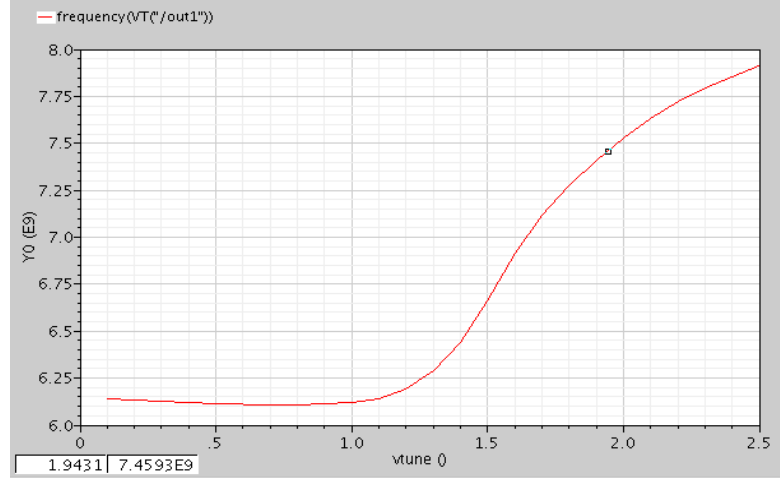

Figure 6. Tuning characteristic of the LC-NMOS VCO

TABLE I: COMPARISON BETWEEN THEORETICAL AND SIMULATION RESULTS

\begin{tabular}{|c|c|c|}
\hline & $\begin{array}{c}\text { Graphical } \\
\text { Optimization }\end{array}$ & Spectre RF Software \\
\hline Frequency (GHz) & 6 & 6.12 \\
\hline Tuning range (\%) & 25 & 25.9 \\
\hline Phase noise(dBc/Hz) & -118.44 & -118 \\
\hline
\end{tabular}

\section{CONCLUSION}

This paper describes a graphical method for the phase noise optimization of LC voltage controlled oscillators. It is based on a three-dimensional phase noise analysis diagram to visualize the different design constraints such as tank amplitude, startup condition and tuning range. It is shown that the design process to minimize phase noise and to obtain optimum bias condition through this illustration and using graphical optimization presents simulated accurate and systematic results. The optimized VCO achieves a phase noise of $-118 \mathrm{dBc} / \mathrm{Hz}$ at $1 \mathrm{MHz}$ frequency offset for a 6.12 $\mathrm{GHz}$ carrier frequency.

\section{REFERENCES}

[1] D.Ham, and A. Hajimiri, "Concepts and methods in optimization of integrated LC VCOs" IEEE J.Solid-State Circuits, Vol 36, no. 6,pp. 896-909, Jun. 2001.

[2] A. Hajimiri and T.H. Lee, "Design issues in CMOS differential LC oscillators" IEEE J.Solid-State Circuits, Vol 34, no. 5,pp. 896-909, May. 1999.

[3] D. Cordeau, JM. Paillot, « Minimum phase noise of an LC oscillator : determination of the optimum operating point of the active part », AEU, International journal of electronics and communications, vol.64, $n^{\circ}$, pp. 795-805, september 2010.

[4] G. Astis, D. Cordeau, J.M. Paillot and L. Dascalescu, "A 5 GHz fully integrated Full PMOS Low-phase-noise LC VCO” IEEE J.Solid-State Circuits, vol.40, no.10,october 2005.

[5] B. Soltanian and P. Kinget, "A tail current-shaping technique to reduce phase noise in LC-VCO” IEEE Custom Integrated Circuit Conference, pp. 579-582, 2005.

[6] T. H. Lee, "The design of CMOS radio-frequency integrated Circuits" Cambridge University Press, 1998.

[7] I.Krout, H. Mnif, M. Fakhfakh and M. Loulou, "A novel heuristic for the optimal design of LC Voltage Controlled Oscillators", IEEE Electronics Circuits and Systems, ICECS, pp. 396-399, Sep 2008. 